\title{
A formação do/a educador/a social que atua em instituições de acolhimento: um estado da arte (2009-2019)
}

\author{
Léslie Amanda da Silva ${ }^{1}$ \\ Fabiane Freire França ${ }^{2}$ \\ Solange Franci Raimundo Yaegashi ${ }^{3}$
}

\begin{abstract}
RESUMO
O objetivo deste artigo é apresentar um estado da arte sobre a formação dos/as educadores/as sociais que atuam em instituições de acolhimento, com o recorte temporal de 2009 a 2019. As pesquisas foram mapeadas no banco de periódicos da Coordenação de Aperfeiçoamento de Pessoal de Nível Superior (CAPES) e nas plataformas de difusão científica online Scielo e Google Acadêmico. Os resultados encontrados evidenciam a necessidade de pesquisas sobre a formação dos/as educadores/as sociais, visto que desde o Projeto de Lei 5346, apresentado no ano de 2009, foi proposta a regulamentação profissional da educação social no Brasil. Constatou-se que até a presente data, o Projeto de Lei 2941/2019, que também trata da regulamentação da profissionalização dos/as educadores/as sociais encontra-se em tramitação e aguarda a aprovação do Congresso. Dessa forma, as pesquisas encontradas dialogam com as legislações que são abordadas pelas autorias e propiciam discussões acerca da formação do/a educador/a social e sua atuação em instituições de acolhimento.
\end{abstract}

PALAVRAS-CHAVE: Educadores/as Sociais. Estado da Arte. Instituição de Acolhimento. Pedagogia Social.

\footnotetext{
${ }^{1}$ Mestranda em Educação. Universidade Estadual de Maringá, Maringá, PR, Brasil. Orcid. https://orcid.org/0000-00030770-2710. E-mail: pesquisadoraleslie@gmail.com.

${ }^{2}$ Doutora em Educação. Docente do Programa de Pós-Graduação em Educação da Universidade Estadual de Maringá, Maringá, PR, Brasil. Orcid. https://orcid.org/0000-0001-9781-9773. E-mail: prof.fabianefreire@ gmail.com.

${ }^{3}$ Doutora em Educação. Docente do Programa de Pós-Graduação em Educação da Universidade Estadual de Maringá, Maringá, PR, Brasil. https://orcid.org/0000-0002-7666-7253. E-mail: solangefry@gmail.com.
} 
The formation of social educators in care institutions: state-of-theart situation (2009-2019)

\begin{abstract}
State-of-the-art situation on the formation of social educators in care institutions within the 2009-2019 period is provided. Research works were mapped at databases of scientific journals of the Coordination for the Upgrading of Personnel in Higher Institutions (Capes) and on publication platforms of online Scielo and Google Scholar. Keywords social educator, Care Institutions, Human Rights and Social Pedagogy were employed. Results show the need for further research on the formation of social educators since Law 5346, published in 2009, also proposing the professional regulation of social education in Brazil, still needs discussion and approval by Parliament. Research works focused in current paper maintain a dialogue with legislation discussed by the authors and forward in-depth investigation on the formation of social educators and work in care institutions.
\end{abstract}

KEYWORDS: Social educators. State-of-the-Art. Care Institutions. Social Pedagogy.

La formación del educuador social que trabaja en instituciones de acogida: un estado del arte (2009-2019)

\title{
RESUMEN
}

El objetivo de este articulo és presentar un estado del arte en la formación de los educadores sociales que trabajan en las instituciones de acogida, con el marco temporal de 2009 a 2019. Las investigaciones se mapearon en la base de datos periódica de la Coordinación de Mejoramiento de Personal Educación Superior (CAPES) y en las plataformas de divulgación cientifica online, Scielo y Google scholar. Los resultados encontraron evidencia de la necesidad de investigación sobre la formación de educadores sociales, ya que desde el proyecto de ley 5346, presentado en 2009, se propone la regulación profesional de la educación social en Brasil. Se constato que la fecha, el Proyecto de Ley 2941/2019, que también trata de la regulamentación de los educadores sociales, se encuentra en trámite y espera la aprovación del congreso. De esta manera, la investigación encontro diálogos con las 
leyes que abordan los autores y brindan discusiones sobre la formación del educador social y su desempeño en las instuciones de acogida.

PALABRAS-CLAVE: Educadores Sociales. Estado del Arte. Instituciones de Acogida. Pedagogía Social.

$$
* * *
$$

\section{Introdução}

As discussões que emergem do campo da educação social, como espaço de intervenção, são amplas, por isso, se faz necessária a busca por pesquisas que referenciam tal área por meio de um recorte temático e temporal. É por compreender essa necessidade que a presente pesquisa objetiva possibilitar o diálogo entre pesquisadores/as que desenvolveram seus estudos vinculados à educação, com ênfase no viés da Pedagogia Social e dos Direitos Humanos.

Em vista disso, o presente artigo, caracterizado como Estado da Arte, tem o intuito de apresentar as pesquisas selecionadas nas plataformas do Scientific Electronic Library Online (SciELO), Google Scholar e Periódicos da CAPES. Para Luna (2009), o objetivo do estado da arte é descrever o estado atual de uma dada área de pesquisa. Com efeito, neste texto são apresentadas pesquisas vinculadas à formação dos/as educadores/as sociais e sua atuação em instituições de acolhimento.

Para Ferreira (2002), as pesquisas do estado da arte possuem o desafio de mapear e discutir determinada produção acadêmica. Luna (2009) complementa que pesquisas como estas se constituem como uma ampla fonte de atualização para pesquisas e pesquisadores.

Ao buscar por pesquisas que estejam relacionados com o objeto deste estudo, se fez necessário a revisão dos últimos 10 anos (2009-2019), nas plataformas já citadas, visto que o primeiro Projeto de Lei $n^{0} 5346$, que dispõe sobre a criação da profissão de educador e educadora social, foi elaborado no ano de 2009 e apensado ao Projeto de Lei 2676/2019, sendo que ambos tratam da criação da profissão do/a educador e educadora social e dá outras 
providências. Dessa forma, o critério de seleção do recorte temporal compreende o período de tramitação dos projetos que tratam de um mesmo fim, a regulamentação da profissão do/a educador/a social, que em dez anos está em processo de tramitação.

Para a triagem e seleção dos artigos foi realizada a leitura do resumo, introdução, método/metodologia e considerações finais. Para organizar o material no presente artigo, optou-se por não apresentar cada trabalho de maneira individual, mas agrupá-los em cinco (5) eixos norteadores de discussão e análise, oganizados em tópicos no presente artigo. Dos cincos eixos, três foram organizados como categorias de análise sendo os artigos selecionados agrupados da seguinte maneira: 1) "A Pedagogia Social como ciência"; 2) "A profissionalização da Educação Social: quem é o/a educador/a social?" e 3) "Legislações e o/a Profissional da educação social".

No primeiro eixo de discussão são apresetados os encaminhamentos metodológicos, bem como os critérios de inclusão e seleção dos artigos utilizados para a elaboração das análises. Neste tópico é sistematizado o fluxograma das pesquisas selecionadas e o quadro com a tabulação dos artigos encontrados.

O segundo tópico, denominado "Pedagogia Social como Ciência", evidencia um diálogo entre os autores e as autoras que direcionaram seus estudos para a área da Pedagogia Social, com referência teórica central em Paulo Freire (2018) e Graciani (2014), bem como pesquisadores/as como Santos e Paula (2014), Silva (2016), Paulo, Nachtigall e Goes (2019) que consideram a área da Pedagogia Social como uma ciência que atua e fundamenta as ações dos educadores e as educadoras sociais.

No terceiro eixo de discussões foram agrupadas as pesquisas referentes à profissionalização dos/as educadores/as sociais. Os estudos de Avoglia, Silva e Matos (2012), Azevedo (2019), Barros e Naiff (2015), Cavalcante e Correa (2012) e Pereira (2019) demonstram que há projetos de leis em tramitação, desde o ano de 2009, mas que a regulamentação da profissionalização da educação social é, ainda, uma conquista a ser alcançada. 
Essas discussões se fundamentam no quarto tópico intitulado "Legislações e o/a Profissional da educação social". Por se tratar de uma análise detalhada dos projetos de leis que estão em tramitação, as discussões enfatizam a problemática em relação à formação do/a profissional que atua com crianças e adolescentes em situação de violação de direitos. As pesquisas na área demonstram que o Projeto de Lei n. 5346/2009 de autoria do Deputado Chico Lopes, e, mais recentemente o Projeto de Lei n. 328/2015, proposto pelo Senador Telmário Mota, procuram regulamentar a atividade do educador e da educadora social. Müller e Bauli (2017) assinalam que muitas são as disparidades encontradas na tramitação das propostas normativas, o que ocasionou discussões necessárias entre pesquisadores/as, profissionais e interessados/as na regulamentação da profissionalização dos/as educadores/as sociais.

No quinto e último tópico de discussão do presente artigo são apresentadas as considerações das análises apresentadas em relação aos estudos acerca da área da formação dos/as profissionais que atuam na pedagogia social, com ênfase nos/as educadores sociais e sua atuação em instituições de acolhimento.

\section{Encaminhamentos Metodológicos: critérios de seleção dos artigos}

Realizou-se um mapeamento na base de dados da SciELO, Periódicos da CAPES e Google Acadêmico, com os descritores "Pedagogia Social" or "Instituições de acolhimento" or "Direitos Humanos" or "Educadores Sociais". Como critério de seleção foram tabulados os materiais em língua portuguesa e publicados a partir do ano de 2009. Como mencionado, o recorte temporal se justifica pelo ano que o Projeto de Lei $n^{0} 5346 / 2009$, que propõe a regulamentação da profissão de educador social, foi apresentado à câmara dos deputados e que após dez anos continua em tramitação como PL 2676/2019 que dispõe sobre a 
criação da profissão de educador e educadora social e dá outras providencias, apensado ao PL 2941/2019 que se encontra pronto para a pauta na Comissão de Educação. O último critério foi a seleção de artigos da área da educação, visto que muitos materiais encontrados pertenciam à área das ciências da saúde.

A Scientific Electronic Library Online - SciELO é uma biblioteca eletrônica que abrange uma coleção selecionada de periódicos científicos. Para a seleção dos artigos, foram utilizados como critérios de inclusão: coleções brasileiras, idioma português, ano de publicação (2009-2019), área temática: educação, tipo de literatura: artigo.

Nesta plataforma, com a palavra-chave "Educadores Sociais" (16) foram localizados dezesseis artigos, enquanto que com os jogos de palavras "Educadores Sociais; Instituições de Acolhimento; Direitos Humanos" (0) não foram localizados textos. O mesmo ocorreu com o conjunto de palavras "Educadores Sociais; Instituição de acolhimento" (0). Somente com o termo "Instituição de acolhimento" (4) foram localizados quatro artigos. Já com o jogos de palavras "Instituição de acolhimento; Pedagogia Social" (0) nada foi encontrado. E, por fim, foram mapeados quatro textos com os jogos de palavras "Educador Social; Pedagogia Social" (4) e somente para o termo "Pedagogia Social" (49) foram encontrados quarenta e nove artigos.

O portal de Periódicos da CAPES, com acesso livre e gratuito, foi oficialmente criado pela Coordenação de Aperfeiçoamento de Pessoal de Nível Superior (CAPES), que fornece conteúdo em formato eletrônico, como publicações periódicas, nacionais e internacionais; diversas bases de dados que reúnem trabalhos acadêmicos e científicos, além de patentes, teses e dissertações entre outros tipos de materiais.

Neste portal, como pares de palavras-chave foram utilizadas: "Educadores Sociais; Instituições de acolhimento; Direitos Humanos" (7); "Educadores sociais; Instituição de acolhimento" (12); "Pedagogia Social; Educadores Sociais" (68); "Pedagogia Social; Direitos Humanos" (38); 
"Instituições de acolhimento; Direitos Humanos" (29); "Instituições de acolhimento" (76); "Educadores Sociais" (15).

O Google Acadêmico ou Google Scholar é uma ferramenta de pesquisa da Plataforma Google que permite pesquisar em trabalhos acadêmicos, literatura escolar, jornais de universidades e artigos variados. Nesta plataforma, pela quantidade de pesquisas encontradas, foi preciso realizar uma análise minuciosa, das vinte (20) primeiras páginas disponíveis.

Os jogos de palavras-chave utilizados foram "Educador Social; Instituição de Acolhimento; Direitos Humanos" (2.400); "Educador Social; Instituição de acolhimento" (2.500); "Educador Social; Direitos Humanos" (1.670); "Educador Social" (8.600); "Instituição de acolhimento" (4.900); "Instituição de Acolhimento; Direitos Humanos" (1.100); "Instituição de acolhimento; Pedagogia Social" (1.600); "Pedagogia Social" (10.200); "Pedagogia Social; Direitos Humanos" (7.200); "Pedagogia Social; Educador social" (8.500).

No Google Acadêmico, muitos estudos foram contabilizados, entretanto ao fazer a análise para a seleção, observou-se que as pesquisas encontradas não tinham relação com a formação do/a educador/a social, traziam assuntos específicos na área da saúde, como por exemplo, o trabalho realizado com crianças hospitalizadas e o papel da enfermagem no cuidado de crianças.

Para a elaboração do estado da arte, em um primeiro momento foi realizado o mapeamento e a leitura dos artigos publicados nas plataformas supracitadas, com os critérios já sinalizados. Foram descartadas da tabulação as pesquisas publicadas como trabalho de conclusão de curso, artigos de anais de eventos e pesquisas que se repetiam em mais de uma plataforma. No total, foram selecionados 4 artigos na plataforma Scielo, 2 artigos no banco de periódicos da CAPES e 12 artigos na ferramenta Google Scholar, totalizando 18 pesquisas a serem analisadas como apresentado no fluxograma abaixo: 
FLUXOGRAMA 1: Pesquisas Selecionadas

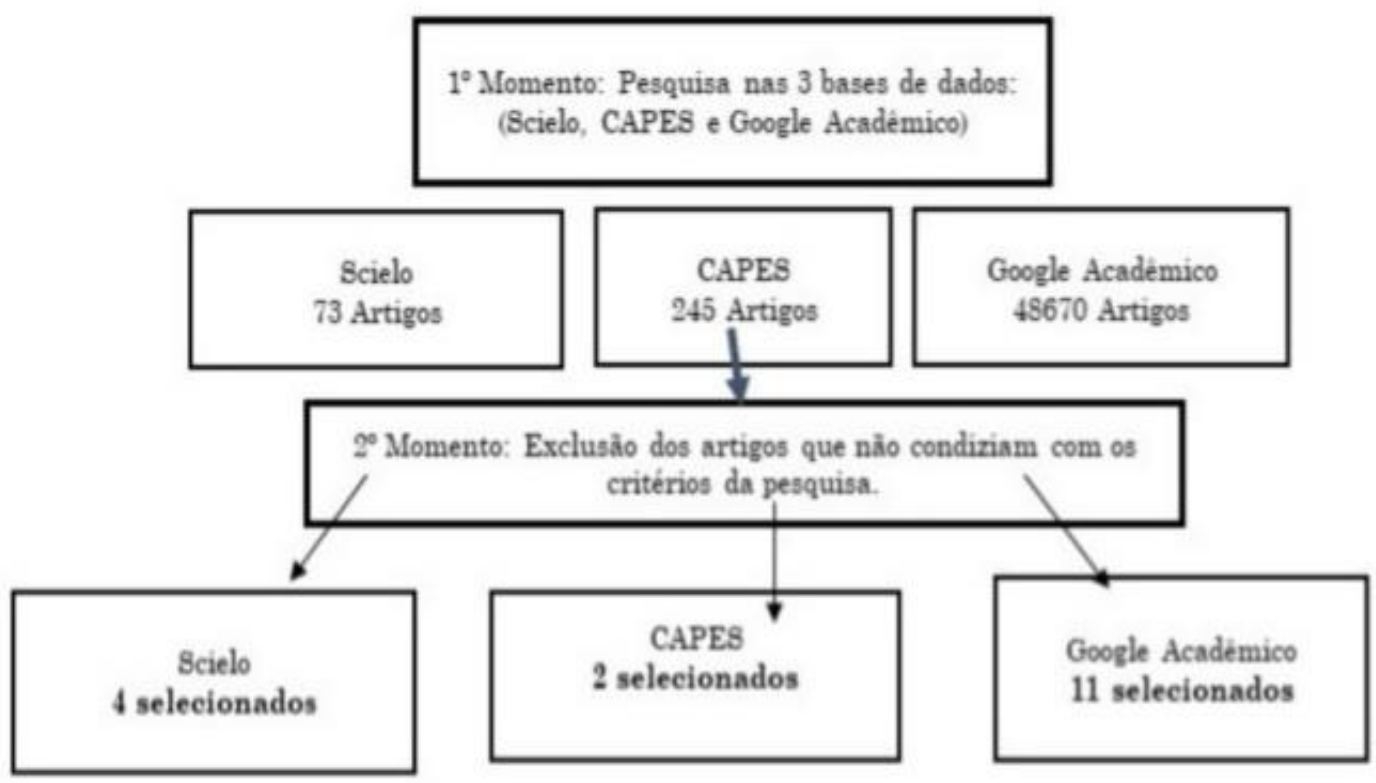

Fonte: Elaborado pelas autoras (2020).

As pesquisas selecionadas foram tabuladas e organizadas de acordo com o título, autorias, periódicos e ano de publicação. Dos dezessete artigos encontrados, com o recorte temporal de 10 anos (2009-2019), constatou-se que as pesquisas estiveram mais voltadas para a formação dos/as profissionais que atuam na Educação Social, com o viés da Pedagogia Social, como apresentado no quadro a seguir:

Quadro 1. Tabulação dos Artigos Selecionados

\begin{tabular}{|l|l|l|l|l|}
\hline $\mathbf{N}^{\mathbf{0}}$ & \multicolumn{1}{|c|}{ Título } & \multicolumn{1}{c|}{ Autorias } & \multicolumn{1}{c|}{ Periódico } & Ano \\
\hline 1 & $\begin{array}{l}\text { Contextos de formação do } \\
\text { educador social no Brasil }\end{array}$ & $\begin{array}{l}\text { UJIIE, N. T.; } \\
\text { NATALI, P. M.; } \\
\text { MACHADO, E. R. }\end{array}$ & $\begin{array}{l}\text { Educação Unisinos, } \\
\text { v. 13, p. 117-124. }\end{array}$ & 2009 \\
\hline \multirow{2}{*}{2} & $\begin{array}{l}\text { Institucionalização de crianças: } \\
\text { leituras sobre a produção da } \\
\text { exclusão infantil, da instituição } \\
\text { de acolhimento e da prática de } \\
\text { atendimento }\end{array}$ & $\begin{array}{l}\text { CINTRA, A. L.; } \\
\text { SOUZA, M. }\end{array}$ & $\begin{array}{l}\text { Revista Mal-Estar e } \\
\text { Subjetividade } \\
\text { (Impresso), v. X, p. } \\
809-833 .\end{array}$ & 2010 \\
\hline \multirow{2}{*}{$\begin{array}{l}\text { Educador social: imagem e relações } \\
\text { com crianças em situação de } \\
\text { acolhimento institucional }\end{array}$} & $\begin{array}{l}\text { AVOGLIA, H. R. } \\
\text { C.; SILVA, A. M.; } \\
\text { MATOS, P. M. }\end{array}$ & $\begin{array}{l}\text { Revista Mal-Estar e } \\
\text { Subjetividade (versão } \\
\text { eletrônica), v. XII, p. } \\
\text { 265-292. }\end{array}$ & 2012 \\
\hline
\end{tabular}




\begin{tabular}{|c|c|c|c|c|}
\hline 4 & $\begin{array}{l}\text { Perfil e trajetória de educadores } \\
\text { em instituição de acolhimento } \\
\text { infantil }\end{array}$ & $\begin{array}{l}\text { CAVALCANTE, L. } \\
\text { I. C.; CORREA, L. } \\
\text { S. }\end{array}$ & $\begin{array}{l}\text { Cadernos de Pesquisa } \\
\text { (Fundação Carlos } \\
\text { Chagas. Impresso), v. } \\
\text { 42, p. 494-517. }\end{array}$ & 2012 \\
\hline 5 & $\begin{array}{l}\text { A teoria de Paulo Freire como } \\
\text { fundamento da Pedagogia Social. }\end{array}$ & $\begin{array}{l}\text { SANTOS, K.; } \\
\text { PAULA, E. M. A. T. }\end{array}$ & $\begin{array}{l}\text { Interfaces Científicas - } \\
\text { Educação, v. 3, p. 33- } \\
44 .\end{array}$ & 2014 \\
\hline 6 & $\begin{array}{l}\text { Capacitação para educadores de } \\
\text { abrigo de crianças e adolescentes: } \\
\text { identificando representações } \\
\text { sociais }\end{array}$ & $\begin{array}{l}\text { BARROS, N. S.; } \\
\text { NAIFF, L. A. M. }\end{array}$ & $\begin{array}{l}\text { Estudos e Pesquisas } \\
\text { em Psicologia } \\
\text { (Online), v. } 15, \text { p. } \\
\text { 240-259. }\end{array}$ & 2015 \\
\hline 7 & $\begin{array}{l}\text { Acolhimento institucional: } \\
\text { considerações sobre a forma como } \\
\text { o cuidado subjetivo se apresenta } \\
\text { no cotidiano de trabalho dos } \\
\text { educadores sociais }\end{array}$ & $\begin{array}{l}\text { FAVERO, C.; } \\
\text { RAZERA, J.; } \\
\text { HAACK, K. R. ; } \\
\text { FALCKE, D. }\end{array}$ & $\begin{array}{l}\text { ALETHEIA } \\
\text { (ULBRA), v. } 47-48, \mathrm{p} \text {. } \\
51-63 .\end{array}$ & 2015 \\
\hline 8 & $\begin{array}{l}\text { A profissionalidade do educador } \\
\text { social frente a regulamentação } \\
\text { profissional da educação social: as } \\
\text { disputas em torno do Projeto de } \\
\text { Lei } 5346 / 2009\end{array}$ & PEREIRA, A. & $\begin{array}{l}\text { Revista Ibero- } \\
\text { Americana de Estudos } \\
\text { em Educação, v. 11, p. } \\
\text { 1294-1317. }\end{array}$ & 2016 \\
\hline 9 & $\begin{array}{l}\text { Os fundamentos freirianos da } \\
\text { pedagogia social em construção } \\
\text { no Brasil. }\end{array}$ & SILVA, R. & $\begin{array}{l}\text { Revista } \\
\text { Interuniversitaria, } \\
\text { núm. } 27 \text {, enero-junio, } \\
\text { p. } 179-198 . \\
\end{array}$ & 2016 \\
\hline 10 & $\begin{array}{l}\text { A importância do educador social } \\
\text { no desenvolvimento psicossocial } \\
\text { da criança institucionalizada }\end{array}$ & $\begin{array}{l}\text { SANCHEZ, M. B. L. } \\
\text { M.; SOUZA, C. B. }\end{array}$ & $\begin{array}{l}\text { CIPPUS - Revista de } \\
\text { Iniciação Científica } \\
\text { da UNILASALLE, v. } \\
05 \text {, p. 11-28, 2017. }\end{array}$ & 2017 \\
\hline 11 & $\begin{array}{l}\text { Crianças como sujeitos de } \\
\text { direitos: uma revisão de } \\
\text { literatura sobre crianças em } \\
\text { situação de acolhimento } \\
\text { institucional }\end{array}$ & $\begin{array}{l}\text { EPIFÂNIO, T. P.; } \\
\text { GONÇALVES, M. V. }\end{array}$ & $\begin{array}{l}\text { Cadernos Brasileiros } \\
\text { de Terapia } \\
\text { Ocupacional, v. 25, p. } \\
373-386 .\end{array}$ & 2017 \\
\hline 12 & $\begin{array}{l}\text { Normatização da profissão do(a) } \\
\text { Educador(a) Social: mitos e } \\
\text { metas. }\end{array}$ & $\begin{array}{l}\text { MÜLLER, V. R.; } \\
\text { BAULI, R. A. }\end{array}$ & $\begin{array}{l}\text { ENSINO \& } \\
\text { PESQUISA, v. } 15, \mathrm{n} . \\
02, \text { p. } 28-42 .\end{array}$ & 2017 \\
\hline 13 & $\begin{array}{l}\text { Terceiro Setor, Instituições de } \\
\text { Ensino e Educadores Sociais: } \\
\text { fomação e práticas pedagógicas }\end{array}$ & SOUZA, J. A. & $\begin{array}{l}\text { REPATS, Brasília, } \\
\text { v.6, n.1, p. 358-377. }\end{array}$ & 2019 \\
\hline 14 & $\begin{array}{l}\text { Educação social: a legitimação de } \\
\text { uma profissão com autoridade } \\
\text { interventiva }\end{array}$ & AZEVEDO, S. & $\begin{array}{l}\text { Laplage em Revista } \\
\text { (Sorocaba), vol.5, n.2, } \\
\text { p. 36-41. }\end{array}$ & 2019 \\
\hline 15 & $\begin{array}{l}\text { O educador social e suas } \\
\text { competências de atuação } \\
\text { profissional: um trabalhador da } \\
\text { Educação pela LDBEN n. }{ }^{\circ} \text { 9.394/96? }\end{array}$ & PEREIRA, A. & $\begin{array}{l}\text { DEBATES EM } \\
\text { EDUCAÇÃO, v. 11, } \\
\text { p. } 311-332 .\end{array}$ & 2019 \\
\hline 16 & $\begin{array}{l}\text { Educação Popular e Educação } \\
\text { Social a partir de Paulo Freire: } \\
\text { conceitos em disputas ou } \\
\text { complementares? }\end{array}$ & $\begin{array}{l}\text { PAULO, F. D. S.; } \\
\text { NACHTIGALL, N. } \\
\text { R. G.; GOES, T. P. }\end{array}$ & $\begin{array}{l}\text { Revista Pedagógica } \\
\text { (Chapecó. Online), v. } \\
\text { 21, p. 43-62. }\end{array}$ & 2019 \\
\hline 17 & $\begin{array}{l}\text { Evolução e perspectivas da } \\
\text { normatização da profissão de } \\
\text { educador social no Brasil }\end{array}$ & $\begin{array}{l}\text { BAULI, R. A.; } \\
\text { MÜLLER, V. R. }\end{array}$ & $\begin{array}{l}\text { Convergencias. } \\
\text { Revista de } \\
\text { Educación., v. 02, p. } \\
\text { 153-171. }\end{array}$ & 2019 \\
\hline
\end{tabular}

Fonte: Elaborado pelas autoras (2020). 
Os materiais selecionados, por terem relações temáticas e teóricas, foram agrupados em três categorias de análise. $\mathrm{Na}$ primeira, "A Pedagogia Social como ciência”, os estudos de Pereira (2016), Azevedo (2019), Santos e Paula (2014) e Silva (2016) discutem formação do educador social pelo viés teórico de Paulo Freire (2018).

Na segunda categoria, "A profissionalização da Educação Social: quem é o/a educador/a social?", as pesquisas de Müller e Bauli (2017), Ujiie, Natali e Machado (2009), Souza e Sanchez (2017), Avoglia, Silva e Mattos (2012), Barros e Naiff (2015), Pereira (2019), Paulo, Nachtigall e Gões (2019), e Epifânio e Gonçalves (2017) enfatizam o Estatuto da Criança e do Adolescente (ECA) e sua relação com o/a educador/a social.

Na última categoria, "Legislações e o/a Profissional da educação social", os estudos de Pereira (2016; 2019), Cavalcante e Correa (2012); Carvalho et al. (2015), Avoglia, Silva e Mattos (2012), Cintra e Souza (2010), Araujo (2019) e Müller e Bauli (2019) são agrupados devido às análises dos projetos de lei em tramitação desde o ano de 2009 que propõe a profissionalização dos educadores sociais e educadoras sociais. Para a análise e discussão dos dados foram explorados como aporte teórico as autorias mais recorrentes nos textos: Freire (2018) seguido de Gracianini (2009).

$\mathrm{Na}$ sequência serão apresentadas as discussões de cada categoria e as análises dos trabalhos reunidos em torno das temáticas em foco.

\section{A Pedagogia Social como ciência}

Nesta primeira categoria contempla-se o diálogo das pesquisas sobre a formação do educador social que atua em instituições de acolhimento e a necessidade de compreender o contexto da educação social e como se constituiu como ciência.

Pereira (2016) pontua que a educação social é um campo de conhecimento "teórico-prático, multirreferencial", que atua em diferentes 
contextos sociais, como por exemplo, em instituições de acolhimento. A ciência dessa educação é chamada de Pedagogia Social. O autor explica que a Pedagogia Social "é uma educação que procura atender todos aqueles que estão ou se encontram em processo de exclusão social, conhecidos como vulneráveis, assistidos, desfiliados" (PEREIRA, 2016, p. 1296).

De acordo com Azevedo (2019), a pedagogia age como ciência, pois trata de critérios e paradigmas das teorias e metodologias da educação. No Brasil, a Pedagogia Social começou a ter destaque a partir da década de 1960, com Paulo Freire (1921-1997), que discutiu em seu livro Pedagogia do Oprimido (1975) teorias de educação popular. De acordo com Freire (2018, p.11),

[...] a educação libertadora é incompatível com uma pedagogia que, de maneira consciente ou mistificada tem sido prática de dominação. A prática da liberdade só encontrará adequada expressão numa pedagogia em que o oprimido tenha condições de, reflexivamente, descobrir-se e conquistar-se como sujeito de sua própria destinação histórica.

A educação libertadora é retratada na atuação da Pedagogia Social e, para Santos e Paula (2014), se faz necessário destacar que esta área da educação propõe discutir o atendimento a todas as pessoas em condição de vulnerabilidade social, independente de classe social e condições financeiras. O que é fundamentado por Silva (2016), ao conceituar a Pedagogia Social e sua relação com o pensamento pedagógico de Paulo Freire.

A concepção de uma Pedagogia Social fundamentada no pensamento pedagógico de Paulo Freire representa uma importante contribuição para a pesquisa, análise e reflexão das ricas e diversificadas práticas de educação popular, comunitária e social oriundas dos movimentos sociais e populares, por vezes fragilizadas por falta de fundamentação teórica, marginalizada pela academia, desprovida de instâncias de formação e com produção completamente fragmentada, sem nenhuma organicidade teórica ou conceitual (SILVA, 2016, p. 188-189). 
Santos e Paula (2014) ainda complementam que a Pedagogia Social não é apenas um processo de escolarização, "mas um processo político que contribui para a existência humana" (SANTOS; PAULA, 2014, p. 37). Nessa perspectiva, Pereira (2016, p. 1296-1297) afirma:

[...] a educação social se define como uma prática educativa que busca a integração dos diversos indivíduos e grupos marginalizados, lutando para que estes sejam considerados como sujeitos de direitos; portanto, uma educação que está, concomitantemente, dentro e fora dos muros da escola, que pertence tanto ao campo das práticas pedagógicas formais, sem deixar de sensibilizar-se pelas informais.

O conjunto de artigos que compõe esta categoria de análise tem como ênfase a Pedagogia proposta por Paulo Freire e sua contribuição social aos grupos sociais menos favorecidos economicamente. Evidenciam ainda uma preocupação com uma formação, tanto do educador/a quanto do educando/a, que seja humanizadora e libertadora.

É por discutir sobre esta prática educativa e humanizadora, que se faz necessário pensar na profissionalização dos/as educadores/as sociais que trabalham em instituições de acolhimento, que atuam na educação social. Pois, são estes/as profissionais que estarão junto com as crianças e adolescentes que se encontram em situação de violação de direitos, o que é fundamentado no tópico abaixo ao propor uma análise acerca dos/as profissionais da Educação Social.

\section{A profissionalização da Educação Social: quem é o/a educador/a social?}

Essa categoria de análise evidencia o processo de institucionalização das instituições de acolhimento de acordo com o Estatuto da Criança e do Adolescente. Compreender tal processo se faz necessário, pois com a fundação das instituições de acolhimento é urgente a contratação de profissionais que atuem nesses locais, profissionais estes denominados de educadores e educadoras sociais. 
Ujiie, Natali e Machado (2009), sobre este processo histórico, argumentam que no Brasil, os espaços de educação não formal emergiram no final da década de 1980 e no início da década de 1990, com a promulgação do Estatuto da Criança e do Adolescente.

É com o ECA que o acolhimento institucional passa a ser uma das medidas de proteção previstas aplicáveis para crianças e adolescentes que tiverem seus direitos ameaçados ou violados. Sobre os direitos da criança e do adolescente, o Art. $3^{\circ}$ do ECA, estabelece que:

A criança e o adolescente gozam de todos os direitos fundamentais inerentes à pessoa humana, sem prejuízo da proteção integral de que trata esta Lei, assegurando-selhes, por lei ou por outros meios, todas as oportunidades e facilidades, a fim de lhes facultar o desenvolvimento físico, mental, moral, espiritual e social, em condições de liberdade e de dignidade (BRASIL, 1990).

Conforme argumentam Epifânio e Gonçalves (2017), o abrigo de acordo com o ECA, é uma medida provisória e excepcional, utilizado apenas em casos de grave risco à integridade da criança e do adolescente. É neste contexto que atualmente há diferentes instituições de atendimento à criança e adolescente que se encontram em vulnerabilidade. Para Souza e Sanchez (2017), o abrigo, a casa de passagem ou casa transitória, a casa lar, repúblicas ou pensões têm cumprido o papel de cuidar desses indivíduos. Como sujeito responsável por garantir esse cuidado, o/a educador/a social é o/a profissional que estará à frente das instituições de acolhimento, promovendo o zelo diário das crianças e adolescentes institucionalizados.

A figura do educador é fundamental, pois ele é o responsável pela rotina que as crianças terão dentro e fora da instituição, ao se responsabilizar por tarefas que visam promover a saúde, alimentação e educação dessas crianças (SOUZA; SANCHEZ, 2017, p.14).

Avoglia, Silva e Mattos (2012) explicam que o educador social é a referência mais próxima de adulto, após o afastamento da criança e do 
adolescente de sua família. As autoras ainda ressaltam a importância da relação entre educador ou educadora com os sujeitos institucionalizados, entretanto, enfatizam a necessidade da formação continuada para os/as educadores/as sociais. "[...] o abrigo e seus profissionais não devem jamais pretender competir com a família” (BARROS; NAIFF, 2015, p. 244). Cabe ao educador social possibilitar um ambiente favorável que garanta os direitos das crianças e adolescentes e seu pleno desenvolvimento.

A formação do educador social é um desafio a ser enfrentado, pois desde os anos de 1980-1990 o profissional social começou a ter maior visibilidade perante a educação, todavia, sua atuação não exigia uma formação ampla.

A formação do educador social é um aspecto que merece reflexão mais cuidadosa, visto que, como lembramos, sua formação não é um pré-requisito para a atuação. Compreendemos que a formação do educador social deve ser ampla e precisa contemplar conhecimentos específicos sobre educação não formal, além de uma sólida e crítica formação política (UJIIE; NATALI; MACHADO, 2009, p. 121).

Nesse sentido, Pereira (2016) menciona que para ser um educador social é necessário apenas um desejo de mudança e emancipação das crianças e adolescentes que eram abandonados ou retirados da sua família de origem e encaminhadas para os abrigos sociais. Em sua pesquisa, "O educador social e suas competências de atuação profissional: um trabalhador da educação pela LDBEN No 9394/96?", apresenta que a luta é ver regulamentada sua profissão.

No entanto, esse profissional também enfrenta outra luta que é a de ver regulamentada a sua profissão para que goze de todos os direitos inerentes seu trabalho. Um dos principais enfrentamentos está na definição do campo de atuação profissional: educação ou trabalho social? A sua atuação tem demonstrado um pertencimento educativo, indicando que se trata de um (a) trabalhador (a) da educação, embora, em tese, não seja contemplado na LDBEN 9394/96 (PEREIRA, 2019, p. 317). 
As pesquisas que compõem esta categoria de análise sinalizam que o trabalho do/a educador/a social é significativo para a vida do sujeito institucionalizado. Em vista disso, o estudo de Paulo, Nachtigall e Gões (2019, p. 58) considera "a necessidade, importância e urgência de pesquisas que discutam a relação entre os conceitos educação popular e educação social e o uso de Paulo Freire”.

As pesquisas que fazem parte da categoria seguinte, se fundamentam em aportes legislativos e documentos normativos para compor as discussões. É válido ressaltar que abordar estes documentos e legislações, se torna viável para analisar as próprias diretrizes e propiciar maior diálogo em torno da profissionalização dos educadores/as sociais e outras providências que são propostas nos projetos de Leis já mencionados.

\section{Legislações e o/a Profissional da educação social}

Essa categoria de análise engloba as pesquisas sobre a profissionalização do educador social. Verifica-se, por meio dos artigos mapeados, que passam dos dez anos a tramitação do processo de regulamentação da profissão do/a educador/a social. Atualmente com as transformações ocorridas no trabalho social, torna-se imprescindível profissionalizar o/a educador/a social. É por esse viés, que nas pesquisas de Pereira $(2016 ; 2019)$ há uma ênfase no Projeto de Lei da Câmara Federal $n^{\circ}$ 5346/2009 e no Projeto de Lei do Senado Federal n ${ }^{\circ} 328 / 2015$ que propõe regulamentar a profissão de Educador Social.

Nesse contexto, a regulamentação da profissão de educação social vai impactar diretamente no mercado de trabalho e na valorização desse trabalhador, quando da obrigatoriedade da aquisição de conhecimentos e saberes que potencializará as habilidades e competências para o trabalho social, aumentando o nível de exigência na contratação desse profissional e os ganhos salariais (PEREIRA, 2016, p. 1304). 
Nos Projetos de Lei mencionados ficam explícitos os atributos individuais necessários ao trabalho do educador social, entretanto é no Projeto de Lei do Senado que são tratadas as competências fundamentais para atuar na área da pedagogia social.

Art. $3^{\circ}$ São atribuições dos profissionais de que trata esta Lei ações de educação e mediação que envolvam os direitos e deveres humanos, a justiça social e o exercício da cidadania com pessoas de qualquer classe social, gênero, idade, etnia, cultura, nacionalidade, dentre outras particularidades, por meio da promoção cultural, política e cívica (BRASIL, 2015).

Vale ressaltar, que mesmo com a implementação da legislação que dispõe sobre a profissão de educador e educadora social, ainda se faz necessário analisar alguns apontamentos, como mencionados na pesquisa de Cavalcante e Correa (2012). As autoras, ao realizarem um estudo qualitativo com educadores/as sociais de um abrigo, elencaram nos resultados a frustração mencionada pelos/as educadores/as entrevistados/as. Nesse estudo, as/os educadores/as sociais

[...] atribuíram o sentimento de frustração a problemas cronicamente presentes na instituição: a falta de respeito e de apoio institucional à figura do funcionário que lida diretamente com crianças que possuem características e condições biopsicossociais distintas entre si (CAVALCANTE; CORREA, 2012, p. 507).

As pesquisas que compõe esta categoria evidenciam que, para muitos/as educadores/as, iniciar o trabalho em uma instituição de acolhimento é ter a função de educar, todavia, acabam perdendo seu objetivo pedagógico e atuam como cuidadores/as. Nessa acepção, Avoglia, Silva e Mattos (2012, p. 277) consideram que os educadores sociais além da educação, valores que destinarão às crianças e adolescentes institucionalizados, também deverão suprir algumas de suas necessidades afetivas, "oferecendo não só uma visão de família como também a representação de papéis familiares”. 
É neste contexto, que os/as autores/as têm mostrado a dicotomia que os profissionais da Pedagogia Social ainda denunciam entre cuidar e educar, como se ambas palavras não estivessem correlacionadas com a construção e formação da identidade do sujeito. Para Hall (2019, p. 11-12), "a identidade torna-se uma celebração móvel: formada e transformada continuamente em relação às formas pelas quais somos representados ou interpelados nos sistemas culturais que nos rodeiam".

Se as identidades são formadas pelos mundos culturais que os sujeitos habitam, como é exposto por Hall (2019), e assim transformadas, a criança e o adolescente institucionalizados constroem suas identidades antes e depois do acolhimento social. Eis a importância dos processos de identificação, conforme apontam Cintra e Souza (2010). Segundo as autoras,

[...] a existência de um outro que se oferece como lugar de escuta e realiza investimentos que vão além de interesses funcionalistas é indispensável para que crianças que estão em instituições tenham chance de ressignificar suas experiências, evitando, assim intervenções que visem simplesmente esconder, apagar a imagem da miséria humana, que tende a ser tomada como inerente aos excluídos pela ordem social (CINTRA; SOUZA, 2010, p. 826).

Para crianças institucionalizadas, o outro exteriorizado da cultura e da sociedade é o/a educador/a social, e é por isso, que é fundamental que este profissional tenha uma formação ampla para assumir determinada função, o que não é proposto no Projeto de Lei 5346/2009, aprovado no ano de 2017. Porém, é no Projeto de Lei $n^{\circ} 328 / 2015$, aprovado em 2019, que a formação do educador ou educadora social se coloca como necessária a especialização em nível superior.

Ao definir o campo de atuação dos educadores sociais, uma das emendas procurou deixar claro que os profissionais devem exercer ações de educação e mediação no campo dos direitos e deveres humanos, da justiça social e do exercício da cidadania. [...] Outra emenda apresentada por Paim exige nível superior para quem ingressar na carreira após a transformação do projeto em lei. Mas admite nível médio como escolaridade mínima para os educadores que já estiverem em atuação na data de publicação da norma. (ARAÚJO, 2019, p. 01). 
Em janeiro do mesmo ano que o Projeto de Lei 5346/2009 foi sancionado, os educadores e educadoras sociais foram incluídos na Classificação Brasileira de Ocupações (CBO). Para Bauli e Müller (2019, p. 158), a CBO é de fácil acesso, pois está inserida no site do Ministério do Trabalho, no qual "[...] é possível obter um relatório por família ocupacional, que aponta a relação de todas as atividades que o Educador Social e os demais profissionais têm por incumbência desenvolver”. Para o educador social são definidas as seguintes funções de acordo com o CBO 5153-05:

5153-05- Educador Social. Visam garantir a atenção, defesa e proteção a pessoas em situações de risco pessoal e social, procuram assegurar seus direitos, abordando-as, sensibilizandoas, identificando suas necessidades e demandas e desenvolvendo atividades e tratamento (BRASIL, 2015).

Para os deputados que participaram da construção do Projeto de Lei, este foi para os educadores sociais "sua mais importante conquista no processo de reconhecimento social e profissional e no fortalecimento de sua identidade trabalhista" (BRASIL, 2015, p. 8).

Pereira (2019) argumenta que o/a educador social é um trabalhador do âmbito educacional, porém, é essencial que haja critérios mais rigorosos na contratação desses profissionais, aliás, serão estes responsáveis pela promoção dos direitos humanos na instituição que atuará.

Os resultados da pesquisa desenvolvida por Carvalho et al. (2010), revelam que com a contratação de profissionais exclusivamente da área da educação, há uma melhora significativa na compreensão dos fenômenos comuns da instituição de acolhimento. Destarte de que os/as educadores/as que possuíam formação superior mostraram maior compreensão do sujeito institucionalizado, além de apresentar propostas de trabalho adequadas.

Os autores ainda afirmam que há uma problemática em questão, pois quando a perspectiva técnica está somente centralizada na educação, perde- 
se a oportunidade de compreender a criança e o adolescente institucionalizados sob outras dimensões importantes.

A formação continuada está prevista por Lei. [...] Esse investimento deficitário para partir inclusive dos profissionais, quando remetem que não há um ganho secundário em participar dos treinamentos que são convidados. Esse dado pode estar ligado, inclusive, a uma certa falta de esperança e de credibilidade no trabalho que vem sendo realizado, por depararem-se diariamente com o reflexo dos problemas sociais e emocionais os quais são acometidas essas crianças e adolescentes (CARVALHO; et al, 2010, p. 60).

O Projeto de Lei do Senado n ${ }^{0} 328 / 2015$ originou o Projeto de Lei 2676//2019 que dispõe sobre a criação da profissão de educador e educadora social e dá outras providências. Nesse sentido, o

[...] PL n $\mathrm{n}^{0}$ 2.676, de 2019, de autoria da ilustre Deputada Luizianne Lins, exige a formação de nível médio e o PL n ${ }^{\circ} 2.941$, de 2019, de iniciativa do Senador Telmário Mota exige a formação, de nível superior, embora admitida a escolaridade mínima de nível médio para aqueles que estiverem no exercício da profissão quando da entrada em vigor da Lei (BRASIL, 2019).

A Comissão de Educação, aprovou no ano de 2019 o Projeto de Lei $\mathrm{n}^{\circ}$ 2941, de 2019 e rejeitou o Projeto de Lei 2676, de 2019. Porém, foram anexadas emendas que estabeleceram escolaridade mínima de nível médio para o exercer a profissão de educador ou educadora social e observar a escolaridade do profissional se este atuar na elaboração de planos de cargos, carreiras e salários.

Infelizmente após as análises aqui apresentadas, das pesquisas que fazem parte dessa categoria e abordam os projetos de leis que tratam da profissionalização da educação social, ainda não há a promulgação da Lei que regulamenta a profissionalização do/a educador ou educadora social.

Graciani (2009), pesquisadora da Pedagogia Social, afirma que é fundamental analisar a prática educativa dos profissionais que atuam nas instituições de acolhimento, entretanto, aqueles profissionais que 
privilegiarem a vida, o ser humano como sujeito, enxergando a possibilidade de construção de uma nova história social, são os que contribuirão para a uma prática educativa, emancipadora e como proposto por Paulo Freire (2018): "uma educação libertadora".

\section{Considerações Finais}

Os estudos selecionados e analisados neste estado da arte demonstram que se passaram mais de dez (10) anos desde o primeiro Projeto de Lei $\mathrm{n}^{\circ}$ 5346/2009 que propunha a regulamentação da profissionalização do educador/a social. Além disso, as pesquisas mapeadas demonstram uma lacuna a ser preenchida, em relação à formação e atuação desse/a profissional.

É neste contexto que os artigos selecionados evidenciam a necessidade de pesquisas na área da Pedagogia Social, sobretudo nos cursos de formação docente e cursos de licenciatura. A Pedagogia Social, como ciência da educação social, visa promover e garantir o bem estar e a promoção dos valores humanos do sujeito acolhido. Mas, em contrapartida, mesmo que a formação continuada desse profissional seja proposta em Projeto de Lei, ainda em tramitação, poucos são os/as profissionais que sentem a necessidade de ampliar os conhecimentos na área da Pedagogia Social, o que é demonstrado pelos estudiosos dessa temática, como Graciani (2014) e Müller e Bauli (2017; 2019).

Além disso, os artigos selecionados demonstraram a necessidade do aumento de pesquisas sobre a Educação Social na área das Ciências Humanas, pois a maioria das pesquisas está concentrada no campo da Psicologia e das Ciências Sociais e da Saúde.

Ao considerar o presente estudo, verifica-se a ausência de políticas públicas que tratam da educação em direitos humanos e a necessidade de ações que forneçam aos educadores/as sociais formação continuada. É imprescindível que esse profissional, que atua diretamente com crianças e adolescente em vulnerabilidade social, conheça o processo histórico da luta da defesa da criança e do adolescente estabelecidos pelo ECA, promulgado em 1990. 
Ainda são vagos os caminhos para a promoção de uma educação que promova os direitos humanos na perspectiva da Pedagogia Social. Efetivar uma educação libertadora, de acordo com Paulo Freire (2018), é promover uma educação social, com o objetivo de garantir ao oprimido fazer parte dos processos formativos que englobam a pedagogia como campo da educação social.

Com efeito, este estado da arte possibilita repensar as práticas pedagógicas que englobam a atuação dos/as profissionais em instituições de acolhimento com crianças e adolescentes. Repensar as práticas pedagógicas é refletir sobre a construção e formação deste profissional, e como apresentado pelas pesquisas e fundamentações teóricas já anunciadas, este ainda é um problema a ser enfrentado.

A maior parte das pesquisas apresentadas no presente texto enfatiza a necessidade de que haja formação continuada de profissionais que atuam com crianças e adolescentes que se encontram em violação de direitos e são retirados das suas famílias de origem e encaminhados para instituições de acolhimento, ou seja, que tenham formação acadêmica específica para sua atuação. No Brasil, infelizmente, não há políticas públicas de valorização a esse profissional.

Por fim, a presente pesquisa considera que para além do conjunto de pesquisas selecionadas na bases Scielo, Portal de periódicos da CAPES e Google Acadêmico no período de 2009 a 2019, é importante que sejam consideradas outras plataformas que contemplem pesquisas que abordem a formação do/a educador/a social que atua nos variados espaços institucionais, para que sejam percebidas outras perpectivas, problemáticas e considerações.

\section{Referências}

ARAUJO, J. D. Regulamentação da profissão de educador social é aprovada na CAS. Agência Senado. BRASIL, 2019. Disponível em:

https://www12.senado.leg.br/noticias/materias/2019/04/10/regulamentacaoda-profissao-de-educador-social-e-aprovada-na-cas. Acesso em 12 set. 2020.

AVOGLIA, H.R. C.; SILVA, A. M. ; MATOS, P. M. . Educador social: imagem e relações com crianças em situação de acolhimento institucional. Revista MalEstar e Subjetividade (versão eletrônica), v. XII, p. 265-292, 2012. 
AZEVEDO, S. Educação social: a legitimação de uma profissão com autoridade interventiva. Laplage em Revista (Sorocaba), vol.5, n.2, mai.- ago. 2019.

BAULI, R. A.; MÜLLER, V. R. . Evolução e Perspectivas da Normatização da Profissão de Educador Social no Brasil. Convergencias. Revista de Educación., v. 02, p. 153-171, 2019.

BARROS, N. S.; NAIFF , L. A. M. Capacitação para educadores de abrigo de crianças e adolescentes: identificando representações sociais. Estudos e Pesquisas em Psicologia (Online), v. 15, p. 240-259, 2015.

BRASIL. Projeto de Lei $(P L)$ - 5346/2009. Dispõe sobre a criação da profissão de educador e educadora social e dá outras providências. Câmara dos Deputados, Projetos de leis e outros Proposições. Brasília.

BRASIL. Projeto de Lei (PL) - 2676/2019. Dispõe sobre a criação da profissão de educador e educadora social e dá outras providencias. Câmera dos Deputados, Projetos de leis e outras proposições. Brasília.

BRASIL. Projeto de Lei $N^{o} 2941 / 2019$. Regulamenta a profissão de educador social. Senado Federal. Brasília

BRASIL. Classificação Brasileira de Ocupações. Ministério do Trabalho e Emprego. Portaria $n^{\circ}$ 397, de 09 de outubro de 2002. Aprova a Classificação Brasileira de Ocupações - CBO/2002.

BRASIL. Ministério da Educação. Lei n. ${ }^{\circ}$ 9.394, de 20 de dezembro de 1996. Bases da Educação Nacional. Diário Oficial da União, Brasília, 23 dez. 1996.

CAVALCANTE, L. I. C; CORRÊEA, L.S. . Perfil e trajetória de educadores em instituição de acolhimento infantil. Cadernos de Pesquisa (Fundação Carlos Chagas. Impresso), v. 42, p. 494-517, 2012.

CINTRA, A.L. ; SOUZA, M. Institucionalização de crianças: leituras sobre a produção da exclusão infantil, da instituição de acolhimento e da prática de atendimento. Revista Mal-Estar e Subjetividade (Impresso), v. X, p. 809-833, 2010.

EPIFÂNIO, T. P. ; GONÇALVES, M. V . Crianças como sujeitos de direitos: uma revisão de literatura sobre crianças em situação de acolhimento institucional. Cadernos Brasileiros de Terapia Ocupacional , v. 25, p. 373-386, 2017.

FAVERO, C.; RAZERA, J.; HAACK, K. R.; FALCKE, D. Acolhimento institucional: considerações sobre a forma como o cuidado subjetivo se apresenta no cotidiano de trabalho dos educadores sociais. ALETHEIA (ULBRA), v. 47-48, p. 51-63, 2015. 
FREIRE, P. Pedagogia do Oprimido. - 66. Ed. - Rio de Janeiro/ São Paulo: Paz e Terra, 2018.

GRACIANI. M. S. S. Pedagogia Social de Rua: análise e sistematização de uma experiência vivida. 5. Ed. São Paulo: Cortez, 2015.

HALL, S. A identidade cultural na pós-modernidade. Tradução Tomaz Tadeu da Silva \& Guaciara Lopes Louro - 12 ed. Lamparina, 2019.

MÜLLER, V. R.; BAULI, R. A. Normatização da profissão do(a) Educador(a) Social: mitos e metas. ENSINO \& PESQUISA, v. 15, n. 02, p. 28-42, 2017.

PAULO, F. D. S.; NACHTIGALL, N. R. G.; GOES, T. P. . Educação Popular e Educação Social a partir de Paulo Freire: conceitos em disputas ou complementares?. REVISTA PEDAGÓGICA (CHAPECÓ. ONLINE), v. 21, p. 43-62, 2019.

PEREIRA, A. O educador social e suas competências de atuação profissional: um trabalhador da Educação pela LDBEN n. ${ }^{\circ}$ 9.394/96?. DEBATES EM EDUCAÇÃO, v. 11, p. 311-332, 2019.

PEREIRA, A. A profissionalidade do educador social frente a regulamentação profissional da educação social: as disputas em torno do projeto de Lei 5346/2009. Revista Ibero-Americana de Estudos em Educação, v. 11, p. 1294-1317, 2016.

SANTOS, K. ; PAULA, E. M. A. T. . A teoria de Paulo Freire como fundamento da Pedagogia Social. Interfaces Científicas - Educação, v. 3, p. 33-44, 2014.

SANCHEZ, M. B. L. M.; SOUZA, C. B. . A importância do educador social no desenvolvimento psicossocial da criança institucionalizada. CIPPUS - REVISTA DE INICIAÇÃO CIENTÍFICA DA UNILASALLE, v. 05, p. 11-28, 2017.

SILVA, R. D. Os fundamentos freirianos da pedagogia social em construção no Brasil. Pedagogía Social. Revista Interuniversitaria, núm. 27, enero-junio, 2016, pp. 179-198 Sociedad Iberoamericana de Pedagogía Social Sevilla, España.

SOUZA, J. A. Terceiro Setor, Instituições de Ensino e Educadores Sociais: fomação e práticas pedagógicas. REPATS, Brasília, v.6, n.1, p. 358-377, 2019.

UJIIE, N. T.; NATALI, P. M. ; MACHADO, E. R. . Contextos de formação do educador social no Brasil. Educação Unisinos, v. 13, p. 117-124, 2009. 